\title{
Dynamic Evolution Law of Overburden Rock in Shallow-Buried Super-High Fully Mechanized Working Face and Determination of Support Strength
}

\author{
Yingjie Liu $\mathbb{D}^{1},{ }^{1}$ Haijun Wang, ${ }^{2}$ Qingjie Qi, ${ }^{1}$ Anhu Wang ${ }^{\mathbb{D}},{ }^{1}$ and Youxin Zhao ${ }^{1}$ \\ ${ }^{1}$ China Coal Research Institute, Beijing 100013, China \\ ${ }^{2} X i$ 'an Research Institute of China Coal Research Institute, Xi'an, Shaanxi 710077, China \\ Correspondence should be addressed to Anhu Wang; anhu163@163.com
}

Received 25 April 2021; Revised 1 November 2021; Accepted 9 November 2021; Published 7 December 2021

Academic Editor: Feng Du

Copyright (c) 2021 Yingjie Liu et al. This is an open access article distributed under the Creative Commons Attribution License, which permits unrestricted use, distribution, and reproduction in any medium, provided the original work is properly cited.

The objective of this study was to reveal the law of overburden movement and stress evolution during the mining of super-high fully mechanized mining faces. Based on the 12401 fully mechanized mining face of Shangwan Coal Mine in Shendong, this study conducted research and analysis using the methods of similarity simulation experiment, numerical simulation, and field measurement. The results showed that the maximum and minimum principal stresses in the coal seam in front of the working face are concentrated with the advance of the working face. The degree of stress concentration increases with the increase in the advancing range, and the concentration degree of the maximum principal stress and the change gradient is greater than that of the minimum principal stress. But the range of the peak lead coal wall is lower than that of the minimum principal stress of the peak lead coal wall. The phenomenon of stress recovery exists in the goaf. With the increase in the advancing range of the working face, the degree of stress recovery gradually increases, and the degree of maximum principal stress recovery is higher than that of the minimum principal stress recovery. The large fractures observed near the working face are closely related to the underground pressure, relatively large fractures appear on the surface, and the fractures become narrower near the two pathways. Only caving and fissure zones exist in the thin bedrock overburden, and the bending subsidence zone changes with the bedrock thickness. The support strength of the hydraulic support should not be less than $1.47 \mathrm{MPa}$. This research on the overburden movement and stress evolution law of a super-high fully mechanized mining face can provide theoretical guidance for the exploitation and utilization of extrathick coal seam resources. It has broad engineering prospects.

\section{Introduction}

The rapid development of China's economy and society is linked to energy supply. Coal, as an important source of energy, has played a pivotal role. With the continuous development of coal mining equipment and technology, the emergence of fully mechanized faces with super-large mining heights (above $8 \mathrm{~m}$ ) has improved the resource recovery rate and promoted the upgrading of mining technology and equipment. Because the mechanism of rock failure and instability in the mining process of extrathick coal seams remains unclear, the dynamic evolutions of rock strata movement and stress in stopes have not been well understood in the process of overburden movement and mining. This has a significant impact on the safety of superhigh comprehensive mining faces. Experts and scholars at home and abroad have carried out significant research on the law of overburden movement in working faces with large mining heights. The basic top fracture position of the working face is approximately in front of the working face, and there is a higher layer and similar balance structure with the caving coal in the overlying strata in layered mining. The movement of the rock stratum is a dynamic and gradually varying process [1-4]. With the increase in the mining height and working face width, the roof collapse height increases with the index; this aggravates the free space impact on the overlying rock failure. In comparison, the working face length has less influence on the caving zone. 
The regression formula for the correlation factors of the mining height and working face length provides technical guidance for selecting appropriate supporting measures for the coal face [5-8]. The law of pressure in the comprehensive mining faces of Bulianta and Daliuta coal mines has been studied and summarized. The pressure law appears evidently in the working face with a large mining height in the shallow coal seam. Moreover, when the roof is under pressure, the phenomena of coal wall, roof sinking, and tunnel bottom drum appear $[9,10]$. Through monitoring the displacement of the roof strata from the strata in Sihe and Chengzhuang coal mines and systematically analyzing the position of overburden breaking and its balanced structure, it has been concluded that the basic top fracture position of the high mining face is approximately in front of the working face. Compared with layered mining, there is a higher level and similar balance structure with caving coal. The movement of the strata is a dynamic and gradually varying process [11, 12]; the movement process and evolution after overburden fracture due to a large-mining-height stope have been reproduced through indoor tests. The caving of weak overburden rock stratum was found to depend on the development range of the interlayer separation fractures $[13,14]$. The measurement and analysis of a $7.0 \mathrm{~m}$ comprehensive mining face were conducted, and it was concluded that the subkey layer of the super-high mining face can easily enter the collapse zone; hence, it cannot be a common working face. A stable "masonry beam" structure is formed, and the "cantilever beam" structure is broken periodically [15]. In the direct roof of the overburden of the working face, a dynamic distribution equation for the caving zone was established, and the dynamic distribution characteristics of the caving zone in the goaf were revealed $[16,17]$. Based on the number of microearthquake events and energy distribution recorded by microseismic monitoring technology, the vertical rock was established. The roof movement was divided along direct and horizontal directions to analyze the monitoring results of microearthquakes in the Dongjiahe coal mine. The overburden was divided into six zones along the vertical direction: collapse zone, block area, vertical fracture through the area, vertical fracture zone, delamination zone, and bending subsidence zone [18-20]. Studies on the structural characteristics of stopes with a large mining height have shown that an increase in the mining height has a significant influence on the free space produced after the failure of the overlying rock [21, 22]. Based on the key strata theory, stope overburden structure characteristics, and migration regularity of conducting research, the heights of the caving and fracture zones have been found to significantly influence the distribution of the key strata. For the large mining height fully mechanized coal face, the development height of the fissures between the direct roof and the basic roof is proportional to the mining height. And the greater the mining height, the stronger the stress phenomenon. [23-25]. Based on this characteristic, the concept of the key stratum of the direct roof and its discriminant method have been put forward. Based on the key stratum of the direct roof, the existence of the direct roof is classified, and the working resistance of the support is calculated [26-28].

The working face with a large mining height in the Shendong mining area has been characterized by small buried depth, large mining space, and high disturbance of mining to the overlying rock [29-31]. Previous research results pertaining to the breaking movement law of the overlying strata under the influence of mining in largemining-height working faces provide a certain reference for studying the overlying strata breaking law in the $8.8 \mathrm{~m}$ working face of the aforementioned mining area [32]. However, the $8.8 \mathrm{~m}$ working face is currently the largest fully mechanized working face in the world with a full mining height, and the stope space is twice that of the $7 \mathrm{~m}$ working face; studies on this topic are limited. To effectively control the roof structure and ensure the safe and efficient mining of super-large stope spaces, we performed physical simulations, numerical calculations, and field measurements to study the overburden movement and mining stress distribution during the advancing process of an $8.8 \mathrm{~m}$ super-largemining-height fully mechanized working face in Shangwan coal mine. Through field measurement, theoretical research, similarity simulation, and numerical simulation calculation, the rated working resistance of the hydraulic support is determined to be $26000 \mathrm{kN}$. The results provide valuable engineering references for the mining of similar working faces.

\section{Similarity Simulation Experiment}

2.1. Experimental Scheme. According to the similarity theory, similar materials should be used to prepare models in model experiments, and the main mechanical properties of similar materials are similar to those of the simulation prototype; the mechanical properties of materials should be stable during the experiment to avoid any significant influence of the external environment; the material ratio should be changed regularly, and the mechanical properties should be adjusted. Based on the mechanical properties of rock strata and the actual requirements of this simulation experiment, quartz sand was selected as the aggregate, lime and gypsum as the cement, and mica powder as the rock interval in this study. Table 1 lists the specific parameters of the similarity simulation experiment.

The length, width, and height of the model were 3000 , 300 , and $1680 \mathrm{~mm}$, respectively. The grid lines were laid based on dimensions of $100 \mathrm{~mm} \times 100 \mathrm{~mm}$, with a total of 29 horizontal and 15 vertical grid lines. The displacement monitoring point was at the intersection of the horizontal and vertical grid lines. A total of 435 displacement monitoring points were set in the experiment. Nine stress measuring points were set in the $49.26 \mathrm{~m}$ hard layer and $87.3 \mathrm{~m}$ in the main key layer. Figure 1 shows the layout and size of the stress displacement measuring points. Table 2 presents the prototype and model rock strength and material ratio. 
TABle 1: Parameters of a similarity simulation experiment.

\begin{tabular}{lcc}
\hline No. & Physical quantity & Proportion \\
\hline 1 & Model linearity ratio & $1: 150$ \\
2 & Model stress ratio & $1: 150$ \\
3 & Model time ratio & $1: 12.25$ \\
\hline
\end{tabular}

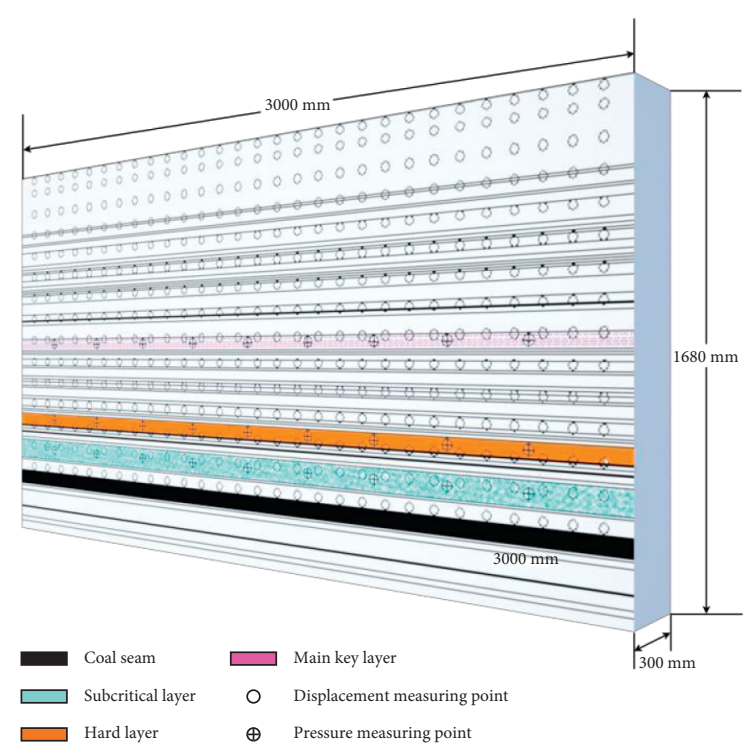

Figure 1: Stress displacement measuring points.

\subsection{Analysis of Results}

2.2.1. Pressure Appearance. Considering the similarity ratio between the field mining progress and the experiment, the model is converted to a distance of $4.6 \mathrm{~cm}$ each time and pushed once every hour. The 12401 working face of the mining starts on the right side, with a propulsion length of $405 \mathrm{~m}$.

With the progress of coal seam mining, the roof begins to bend and sink until breaking down, and the initial pressure and cycle pressure appear. After the first roof caving of the working face, if the caved direct roof cannot be filled with the goaf, with the advance of the working face, the area of the suspended old roof will increase continuously. When the dead weight exceeds the strength limit of the old roof, the basic roof will break off and collapse for the first time, and the working face will appear to come under pressure. When the working face is pushed to $54 \mathrm{~m}$, the basic roof breaks for the first time, and the coal wall is shear damaged. The rock breaks due to the impact of the base plate under the basic roof; however, the block size is still large, as shown in Figure 2.

When the working face advances to $79 \mathrm{~m}$, the first periodic weighting occurs on the basic roof, and the weighting step distance is $24.65 \mathrm{~m}$. The caving zone height is $19.1 \mathrm{~m}$. When the working face is advanced to $96 \mathrm{~m}$, the second periodic weighting occurs on the basic roof, and the weighting step distance is $17.35 \mathrm{~m}$. The strata between the subkey layer and the hard layer begin to bend and sink until stabilizing after contacting with the collapsed strata; however, a large free space is formed above, and the collapse zone height reaches $30 \mathrm{~m}$.

The working face of this model is advanced by $405 \mathrm{~m}$ in total, in which the basic top cycle is pressed 16 times. Table 3 lists the specific parameters. The experimental results show that the first weighting step of the basic roof is $54 \mathrm{~m}$, the periodic weighting step is in the range of $13-30 \mathrm{~m}$, and the first breaking distance of the main key layer is $79 \mathrm{~m}$. Table 2 presents the periodic weighting situation. After full mining, the stoping line direction is $61^{\circ}$, and the opening cut direction is $65^{\circ}$, which presents a symmetrical distribution, and the caving shape is approximately trapezoidal, as shown in Figure 3.

2.2.2. Overburden Movement Law. From the displacement cloud map, we can intuitively see the displacement of each point. The longer the arrow, the greater the displacement.

Based on the displacement data of each monitoring point, shown in Figure 4, when the mining reaches $54 \mathrm{~m}$ and $405 \mathrm{~m}$, the subsidence curve of the roof can be obtained. There is more rock displacement near the coal seam roof, and vice versa, as shown in Figure 5. The developing height of the caving zone in the 12401 working face is $48 \mathrm{~m}$, which is 5.45 times the mining height, and the developing height of the fissure zone is $108 \mathrm{~m}$, which is 12.27 times the mining height. During the advancing of the working face, only the caving and fissure zones exist in the overlying rock where the bedrock is thinner, and the bending subsidence zone changes with the bedrock thickness.

When the working face progresses to $54 \mathrm{~m}$, the maximum deformation in the vertical direction of the surface of the mining working face is $0.137 \mathrm{~m}$, and the maximum surface settlement is directly above the working face. The surface subsidence contour is elliptical, and the maximum subsidence is at the center of the ellipse. The maximum subsidence range of the ellipse is $133 \mathrm{~m}$ along the long axis and $34 \mathrm{~m}$ along the short axis. When the working face advances to $405 \mathrm{~m}$, the surface subsidence contour presents an approximately circular distribution. The maximum displacement reaches $2.38 \mathrm{~m}$. At this time, the surface subsidence value reaches the maximum subsidence value under the geological and mining conditions. The surface is fully mined. The surface subsidence gradually decreases from the inside of the ellipse to the outside, and the diameter of the circular contour line with subsidence of more than $2 \mathrm{~m}$ reaches $143 \mathrm{~m}$.

\section{Numerical Simulation Study on Overburden Movement and Stress Evolution}

Based on the roof and floor conditions of the 12401 working face, a model was established. The length and width of the model are $800 \mathrm{~m}$ and $400 \mathrm{~m}$, respectively. The model height varies with the thickness of the bedrock and the overlying loose layer. The length of the simulated working face is $300 \mathrm{~m}$, and the mining height is $8.8 \mathrm{~m}$. In the simulation process, the broken unit of the overburden is set as an empty grid to simulate the process of overburden collapse. Based on 
TABLE 2: Prototype and model rock strength and material ratio.

\begin{tabular}{|c|c|c|c|c|c|c|c|}
\hline No. & Rock name & $\begin{array}{c}\text { Actual thickness } \\
(\mathrm{m})\end{array}$ & $\begin{array}{c}\text { Model thickness } \\
(\mathrm{cm})\end{array}$ & $\begin{array}{c}\text { Volume force } \\
\left(\mathrm{kN} / \mathrm{m}^{3}\right)\end{array}$ & $\begin{array}{c}\text { Tensile strength } \\
(\mathrm{MPa})\end{array}$ & $\begin{array}{c}\text { Modulus of elasticity } \\
(\mathrm{GPa})\end{array}$ & $\begin{array}{c}\text { Matching } \\
\text { number }\end{array}$ \\
\hline 50 & $\begin{array}{c}\text { Wind-blown } \\
\text { sand }\end{array}$ & 20.85 & 13.90 & 17.00 & 2.38 & 4.00 & 673 \\
\hline 49 & $\begin{array}{c}\text { Sandy } \\
\text { mudstone }\end{array}$ & 1.65 & 1.10 & 24.10 & 3.60 & 18.00 & 673 \\
\hline 48 & Siltstone & 6.05 & 4.03 & 23.80 & 4.45 & 35.00 & 637 \\
\hline 47 & $\begin{array}{l}\text { Sandy } \\
\text { mudstone }\end{array}$ & 4.50 & 3.00 & 24.10 & 3.60 & 18.00 & 573 \\
\hline 46 & Siltstone & 9.76 & 6.51 & 23.80 & 4.45 & 35.00 & 637 \\
\hline 45 & Post stone & 2.44 & 1.63 & 23.90 & 7.20 & 32.00 & 455 \\
\hline 44 & Siltstone & 2.19 & 1.46 & 23.80 & 4.45 & 35.00 & 637 \\
\hline 43 & $\begin{array}{l}\text { Medium } \\
\text { sandstone }\end{array}$ & 1.50 & 1.00 & 24.80 & 6.13 & 38.00 & 637 \\
\hline 42 & $\begin{array}{l}\text { Sandy } \\
\text { mudstone }\end{array}$ & 4.27 & 2.85 & 24.10 & 3.60 & 18.00 & 637 \\
\hline 41 & Siltstone & 4.25 & 2.83 & 23.80 & 4.45 & 35.00 & 637 \\
\hline 40 & $\begin{array}{l}\text { Medium } \\
\text { sandstone }\end{array}$ & 3.85 & 2.57 & 24.80 & 6.13 & 38.00 & 437 \\
\hline 39 & Siltstone & 1.90 & 1.27 & 23.80 & 4.45 & 35.00 & 637 \\
\hline 38 & Post stone & 1.10 & 0.73 & 23.90 & 7.20 & 32.00 & 573 \\
\hline 37 & $\begin{array}{l}\text { Sandy } \\
\text { mudstone }\end{array}$ & 5.20 & 3.47 & 24.10 & 3.60 & 18.00 & 573 \\
\hline 36 & Siltstone & 11.50 & 7.67 & 23.80 & 4.45 & 35.00 & 637 \\
\hline 35 & Post stone & 2.80 & 1.87 & 23.0 & 7.20 & 32.00 & 455 \\
\hline 34 & Siltstone & 9.50 & 6.33 & 24.80 & 6.13 & 38.00 & 437 \\
\hline 33 & $\begin{array}{l}\text { Medium } \\
\text { sandstone }\end{array}$ & 8.14 & 5.43 & 23.80 & 4.45 & 35.00 & 337 \\
\hline 32 & Post stone & 3.50 & 2.33 & 24.80 & 6.13 & 38.00 & 455 \\
\hline 31 & Siltstone & 1.16 & 0.77 & 23.80 & 4.45 & 35.00 & 455 \\
\hline 30 & Post stone & 3.50 & 2.33 & 23.90 & 7.20 & 32.00 & 455 \\
\hline 29 & Siltstone & 4.77 & 3.18 & 23.80 & 4.45 & 35.00 & 455 \\
\hline 28 & Post stone & 1.40 & 0.93 & 23.90 & 7.20 & 32.00 & 455 \\
\hline 27 & Siltstone & 5.82 & 3.88 & 23.80 & 4.45 & 35.00 & 637 \\
\hline 26 & Post stone & 2.16 & 1.44 & 23.90 & 7.20 & 32.00 & 455 \\
\hline 25 & $\begin{array}{l}\text { Medium } \\
\text { sandstone }\end{array}$ & 2.23 & 1.49 & 24.80 & 6.13 & 38.00 & 437 \\
\hline
\end{tabular}

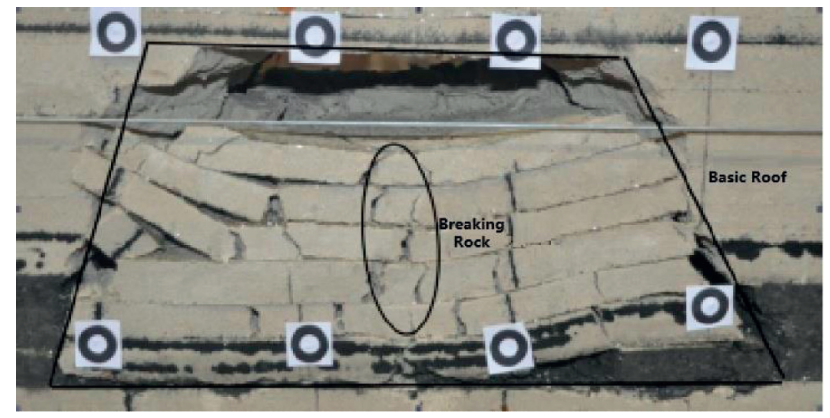

FIGURE 2: First pressure of the basic top of the 12401 working face.

the estimated overburden swelling coefficient, the goaf is filled to simulate the stress recovery phenomenon of the goaf due to overburden movement. The initial stresses imposed in the $x$-direction, $y$-direction, and $z$-direction are $10 \mathrm{MPa}$, $10 \mathrm{MPa}$, and $15 \mathrm{MPa}$, respectively. The burial depth is set to $200 \mathrm{~m}$. Further, the Mohr-Coulomb constitutive model is adopted for the coal and rock, and their mechanical parameters are set, as listed in Table 4.

\subsection{Distribution and Evolution Characteristics of Mining Stress}

3.1.1. Distribution Characteristics of Principal Stress. The maximum principal stress $\sigma 1$ of the original rock is distributed along the $Z$-axis (plumb hammer direction). The maximum principal stress of each rock layer varies under the effect of coal seam excavation. Figure 6 shows the distribution of the maximum main stress of the coal seam under different push schedules. With the advancement of the working face, the maximum concentration of the main stress in the middle of the working face is greater than that at the corner of both ends, while the stress concentration at the upper corner is greater than that at the lower corner (the terrain at the upper corner is higher than that at the lower corner, indicating that the greater the buried depth, the greater the stress concentration degree). Overall, the stress concentration in front of the working area is greater than that behind the goaf, and the stress concentration above the goaf is greater than that under the goaf.

The model shows that the minimum principal stress $\sigma 3$ of the original rock is distributed along the $X$-axis and 
TABLE 3: 12401 working surface cycle to pressure statistics.

\begin{tabular}{lccccc}
\hline $\begin{array}{l}\text { Working face } \\
\text { weighting name }\end{array}$ & $\begin{array}{c}\text { Working face } \\
\text { weighting step }(\mathrm{m})\end{array}$ & $\begin{array}{c}\text { Advancing distance of } \\
\text { working face }(\mathrm{m})\end{array}$ & $\begin{array}{c}\text { Working face } \\
\text { weighting name }\end{array}$ & $\begin{array}{c}\text { Working face } \\
\text { weighting ste }(\mathrm{m})\end{array}$ & $\begin{array}{c}\text { Advancing distance of } \\
\text { working face }(\mathrm{m})\end{array}$ \\
\hline Initial weighting & 54.00 & 54.00 & The 9th time & 30.00 & 261.75 \\
The 1st time & 24.75 & 78.75 & The 10th time & 21.75 & 283.50 \\
The 2nd time & 17.25 & 96.00 & The 11th time & 20.25 & 303.75 \\
The 3rd time & 23.25 & 119.25 & The 12th time & 19.50 & 323.25 \\
The 4th time & 16.50 & 135.75 & The 13th time & 12.75 & 336.00 \\
The 5th time & 27.00 & 162.75 & The 14th time & 21.00 & 357.00 \\
The 6th time & 21.75 & 184.50 & The 15th time & 21.75 & 378.75 \\
The 7th time & 23.70 & 208.20 & The 16th time & 26.25 & 405.00 \\
The 8th time & 23.55 & 231.75 & Average periodic & 22.00 & - \\
\hline
\end{tabular}

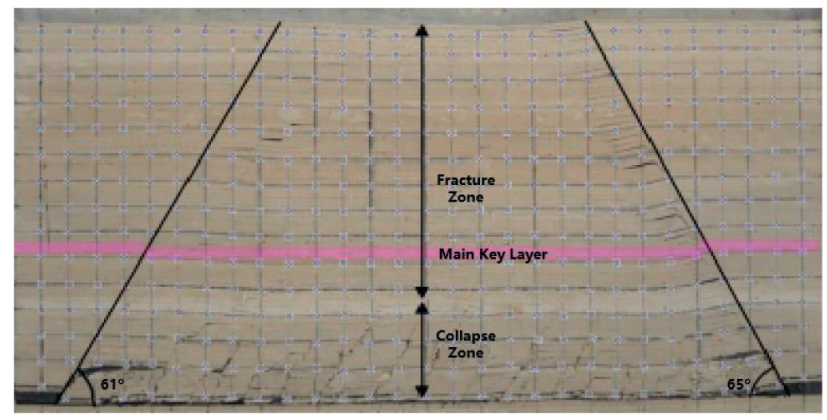

FIGURE 3: 12401 advancement of the working face to $405 \mathrm{~m}$ and the 16th cycle pressure.
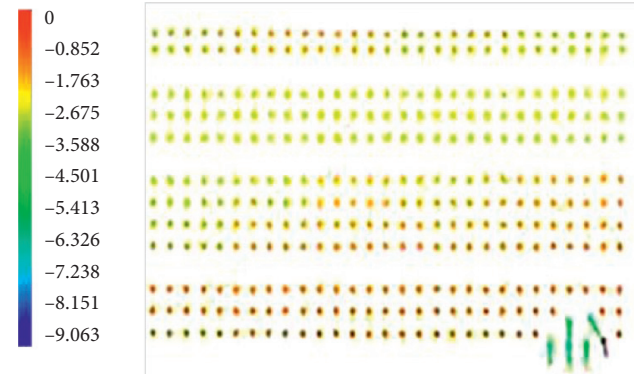

(a)
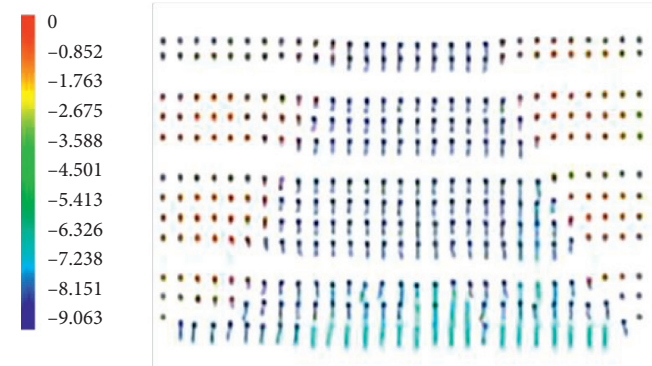

(b)

FIGURE 4: Rock strata above 12401 working face advance displacement with working face. (a) Displacement nephogram of working face advancing to $54 \mathrm{~m}$. (b) Displacement nephogram of working face advancing to $405 \mathrm{~m}$.

affected by the high/low fluctuation characteristics in the west/east of the surface topography. The minimum principal stress of the original rock in the model is high in the west and low in the east. After the coal body is excavated, the minimum principal stress and stress concentration value near the coal body in front of the working face inevitably vary. The goaf behind the working face is partially filled with goaf because of basic roof caving, and the minimum main stress is restored but remains significantly lower than the original value. With the continuous advancement of the working face, a stress concentration phenomenon appears above the coal wall and around the goaf. When the basic roof breaks, the stress concentration phenomenon above the coal wall is alleviated, the stress concentration value and influence range are reduced, and the stress concentration around the goaf slightly changes, as shown in Figure 7. Considering the above phenomena, we analyze the variation characteristics of the minimum principal stress distributions before and after the model is pressurized under different propulsion distance conditions, as follows:

(1) The stress concentration value in the early stage of coal seam mining is relatively low, approximately $16.67 \%$ higher than the original rock stress. When the stress concentration is advanced by $32 \mathrm{~m}$, the influence range of the stress concentration is approximately $75 \mathrm{~m}$ ahead of the coal wall. With the advancement of the working face, the influence range gradually increases, though the increasing rate decreases in the later period: the influence range is approximately $100 \mathrm{~m}$ in front of the coal wall, which is five times higher than that in the $8 \mathrm{~m}$ high working 


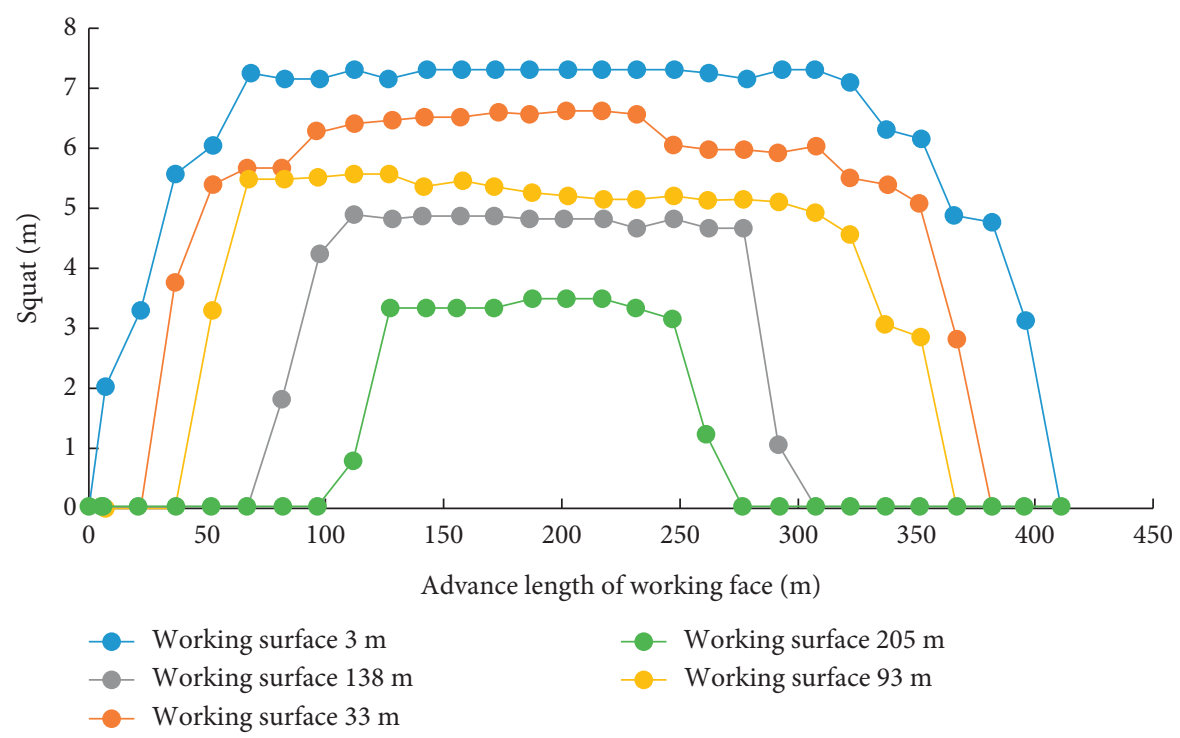

Figure 5: Final subsidence curve of rock stratum at different heights above the working face.

TABLe 4: Physical and mechanical parameters of 1-2 coal seam and its roof and bottom slate in Shangwan coal mine.

\begin{tabular}{|c|c|c|c|c|c|c|c|c|}
\hline $\begin{array}{l}\text { Name of } \\
\text { coal and } \\
\text { rock }\end{array}$ & $\begin{array}{l}\text { True density } \\
\qquad\left(\mathrm{kg} / \mathrm{m}^{3}\right)\end{array}$ & $\begin{array}{c}\text { Apparent } \\
\text { density }\left(\mathrm{kg} / \mathrm{m}^{3}\right)\end{array}$ & $\begin{array}{c}\text { Compressive } \\
\text { strength (MPa) }\end{array}$ & $\begin{array}{l}\text { Tensile } \\
\text { strength } \\
(\mathrm{MPa})\end{array}$ & $\begin{array}{c}\text { Elastic } \\
\text { modulus } \\
(\mathrm{GPa})\end{array}$ & $\begin{array}{l}\text { Poisson's } \\
\text { ratio }\end{array}$ & $\begin{array}{c}\text { Internal } \\
\text { friction angle } \\
\left({ }^{\circ}\right)\end{array}$ & $\begin{array}{c}\text { Cohesion } \\
(\mathrm{MPa})\end{array}$ \\
\hline Basic roof & 2664 & 2537 & 22.79 & 6.72 & 30.94 & 0.27 & 34.30 & 4.99 \\
\hline Direct roof & 2658 & 2516 & 23.80 & 6.30 & 40.31 & 0.23 & 38.49 & 5.26 \\
\hline Coal seam & 1429 & 1339 & 15.98 & 2.10 & 23.87 & 0.25 & 34.66 & 2.32 \\
\hline Coal floor & 2786 & 2420 & 16.11 & 6.37 & 47.35 & 0.22 & 33.22 & 7.63 \\
\hline
\end{tabular}

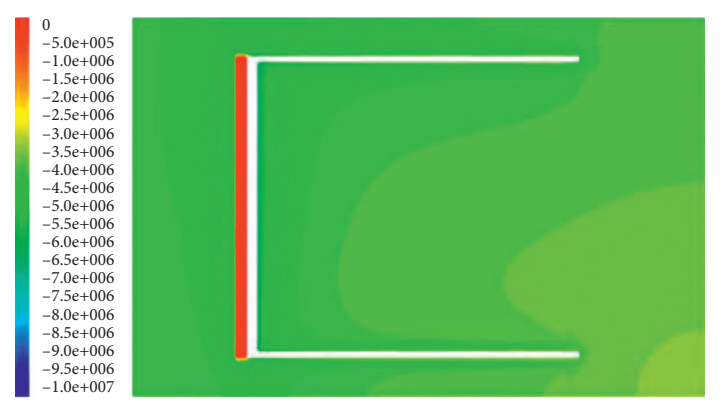

(a)

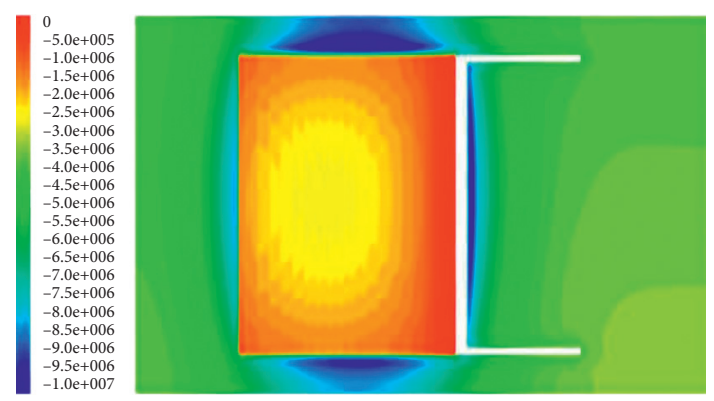

(b)

FiguRE 6: Characteristics of maximum principal stress distribution in different propulsion stages of the working face (left: before pressure; right: after pressure). (a) Advancing to $32 \mathrm{~m}$. (b) Advancing to $320 \mathrm{~m}$.

face of the same coal seam in the adjacent coal seam. With the continuous propulsion of the working face, when the propulsion distance reaches $320 \mathrm{~m}$, the stress concentration value drops back to $2.75 \mathrm{MPa}$.

(2) After the coal seam is mined, a goaf is formed, the pressure is relieved quickly, and the stress is eliminated. With the falling of the straight roof, the basic roof is bent, and the subsidence goaf is filled again. The directly caving roof is filled with the goaf and the basic roof. At this time, the stress reappears. With the advancement of the working face, the stress is gradually restored from the working face direction in the back direction of the goaf. When the unit of pressure is $96 \mathrm{~m}$, the stress in the $40 \mathrm{~m}$ area behind the goaf begins to recover gradually. At this time, the minimum principal stress is approximately $0.25 \mathrm{MPa}$, which is approximately $20 \%$ of the initial original rock stress. The stress recovery value decreases from the ellipse to the surrounding radiation in the middle of the filling area of the goaf. The inclined direction is the long axis of the ellipse, and the direction is the short axis. When the working face 


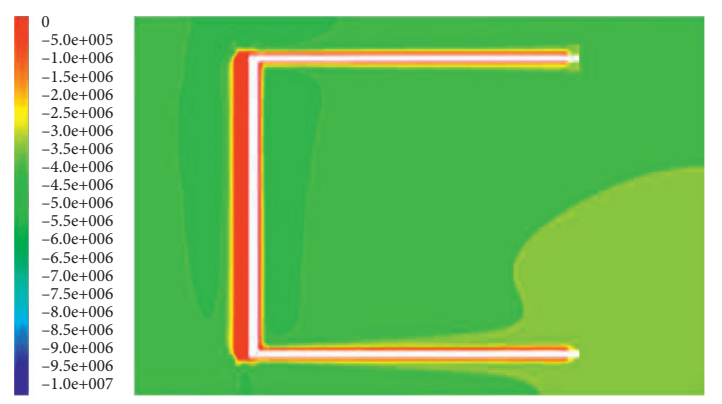

(a)

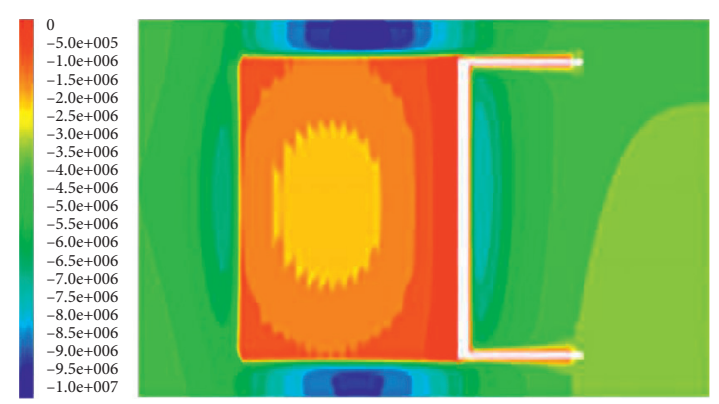

(b)

FIGURE 7: Characteristics of minimum principal stress distribution in different propulsion stages of the working face (left: before pressure; right: after pressure). (a) Advancing to $32 \mathrm{~m}$. (b) Advancing to $320 \mathrm{~m}$.

is pushed to $256 \mathrm{~m}$, the stress recovery value of the goaf reaches $0.75 \mathrm{MPa}$ and is restored to approximately $60 \%$ of the initial value. With the advancement of the working face to the $320 \mathrm{~m}$ stress recovery area, the recovery value of the working face remains unchanged.

(3) Comparing the stress distributions before and after the basic top breaking at different propulsion distances, we find that after the basic roof breaks, the stress concentration value near the coal wall and its influence range are evidently reduced. The weakening effect of the basic top breaking on the stress concentration in the coal wall is particularly prominent after the pushing distance reaches $160 \mathrm{~m}$. The basic roof breaking has a weak influence on the stress concentration on both sides of the goaf and promotes the compaction of the middle and rear of the goaf.

In summary, with the continuous advancement of the working face, an evident stress concentration appears in front of the coal wall; however, the stress concentration degree at the coal wall is weakened after the square is seen, and the basic top breaking alleviates the stress concentration in front of the coal wall.

\subsubsection{Evolution Characteristics of Mining Stress. During the} progress of the working face 12401, the overburden gravity above the goaf is transferred to the surrounding solid coal, thereby increasing the maximum and minimum principal stresses in the solid coal. In the initial mining stage, the concentrations of the maximum and minimum principal stresses are low. With the increase in the advancing range of the working face, the concentrations of the maximum and minimum main stresses gradually increase. The working face is pushed to $200 \mathrm{~m}$, and the concentrations of the maximum and minimum principal stresses become stable. With the increase in the advancing range of the working face, the maximum and minimum principal stresses in the goaf behind the face gradually recover. The wider the mining range, the more complete the overlying rock movement and the higher the recovery degree of the maximum and minimum principal stresses in the goaf. When the working face is pushed to $300 \mathrm{~m}$, the maximum main stress is restored to $2.8 \mathrm{MPa}$, which is approximately $66 \%$ of the original rock stress value, and the minimum principal stress is restored to $0.8 \mathrm{MPa}$, which is approximately $50 \%$ of the original rock stress value.

By analyzing the evolution characteristics of the maximum and minimum principal stresses, it can be concluded that the concentration and gradient of the maximum principal stress in the solid coal in front of the working face are evidently greater than those of the minimum principal stress, while the recovery degree of the maximum principal stress in the goaf behind the working face is also greater than that of the minimum principal stress. The distance between the point of maximum peak stress and the coal wall is significantly smaller than the distance between the point of minimum peak stress ahead of the coal wall, which indicates a wider redistribution range of the minimum principal stress due to mining. In addition, the basic roof breaking has a significant impact on the mining stress concentration. After the basic roof fracture, the peak values of the maximum and minimum main stresses suddenly decrease. This indicates that the violent movement of the overburden causes a sudden release of the mining stress in front of the working face.

3.2. Overburden Movement Characteristics. Figure 8 shows the characteristics of the overburden movement during the pushing process of the 12401 working face. The vertical displacement cloud map of the overburden is provided in the figure from the opening of the hole to advancing $320 \mathrm{~m}$. With the coal seam mining, when the working face is pushed $32 \mathrm{~m}$ (Figure 8(a)), the roof at the cut-off hole has evident vertical displacement, reaching $2.10 \mathrm{~m}$. When the working face is pushed to $64 \mathrm{~m}$, the roof subsidence reaches $4.00 \mathrm{~m}$, the basic roof of the working face is broken, and the vertical displacement of the roof increases at a high rate. When the working face is pushed to $96 \mathrm{~m}$, the roof subsidence reaches $4.50 \mathrm{~m}$, tends to stabilize, and gradually develops to the surface. When the working face is pushed to $128 \mathrm{~m}$, after the second cycle of the basic roof pressure, the roof span falling height increases evidently, the subsidence area of the surface expands, and the roof subsidence tends to stabilize to $5.50 \mathrm{~m}$. When the working face is pushed to $192 \mathrm{~m}$, the maximum subsidence of the roof gradually extends to the surface, the subsidence area of the surface expands evidently, and the subsidence of the roof tends to stabilize to $5.50 \mathrm{~m}$. With the 

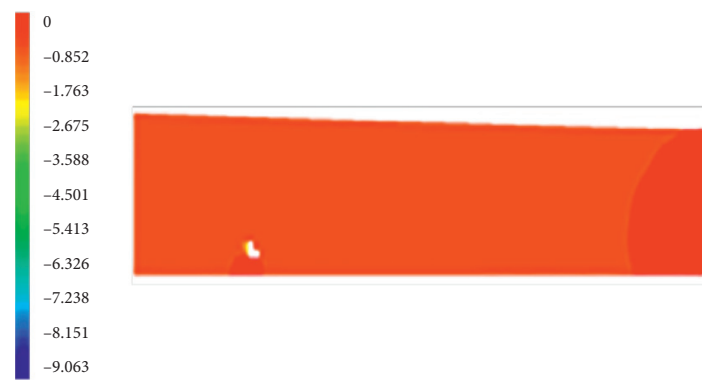

(a)
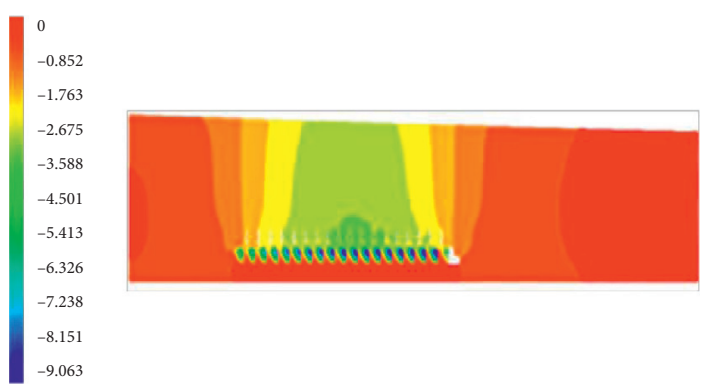

(b)

FIGURE 8: Characteristics of overburden movement in different propelling stages of the working face. (a) $32 \mathrm{~m}$. (b) $320 \mathrm{~m}$.

working face advancing to $320 \mathrm{~m}$ (Figure $8(\mathrm{~b})$ ), a subsidence basin appears on the surface, with the subsidence reaching $4.40 \mathrm{~m}$ and the subsidence of the top plate of the working face reaching $6.0 \mathrm{~m}$. (Figure 9).

\subsection{Characteristics of Overburden Caving. Figure 10 shows} the characteristics of overburden caving during the advancing process of the 12401 working face: when the working face advances to $32 \mathrm{~m}$, the basic roof is pressed for the first time. Because of the narrow mining range, the overburden is disturbed to a low extent, and the overburden caving range is narrow, including only the direct roof, the basic roof, and a small number of follow-up strata above, and the caving height is approximately $15 \mathrm{~m}$. When the advancing range of the working face is between $64 \mathrm{~m}$ and $96 \mathrm{~m}$, the roof falling range remains unchanged in the longitudinal direction and only expands laterally in the advancing direction of the working face. This is because the basic roof is the first key layer that controls the overburden movement. In this stage, the second subkey layer above the basic roof remains undamaged, and the second subkey layer controls the rock above it, which ensures that the upper strata do not collapse. Therefore, the collapse range in this stage does not change in the longitudinal direction, and the collapsed overburden is only the basic roof and the upper strata, the following strata between the second subkey strata. When the working face advances to $128 \mathrm{~m}$, the second subkey layer in the overburden is broken, the overburden caving range shows an increasing trend in the longitudinal direction, and the caving height increases to $43 \mathrm{~m}$. Thereafter, the caving overburden, due to crushing and swelling phenomena, fills the goaf completely and has a supporting effect on the higher strata. The collapse range of the overburden no longer changes. With the movement of the higher strata, the collapsed gangue is gradually compacted, resulting in a stress recovery phenomenon of the goaf.

\section{Field Engineering on Pressure Behavior and Overburden Migration Law}

\subsection{Analysis of Mine Pressure Manifestation Characteristics}

4.1.1. Roof Pressure Characteristics of First Weighting. During the initial mining period, after the 12401 working face pushes out the open cut, the roof gradually collapses.
After the direct roof caving of the goaf is complete, the mining height is maintained in the range of $6.5-7.0 \mathrm{~m}$, and the maximum support pressure reaches a range of 490-510 bar, exceeding the opening value of the safety valve by $47.2 \mathrm{MPa}$. From the analysis, the length of the first weighting push in the 12401 working face is $45 \mathrm{~m}$ (excluding the width of the cut by $11.4 \mathrm{~m}$ ), and the weighting lasts for $5.6 \mathrm{~m}$. Figure 11 shows the resistance distribution of the primary pressure support.

4.1.2. Period of Periodic Weighting. The advancing speed of the working face is related to the weighting step. The advancing speed is low, the weighting step is short, and the weighting step increases as the advancing process accelerates; each weighting has evident weighting and nonweighting limits, and nonweighting generally does not exceed $300 \mathrm{bar}$. When advancing to a distance range of 130-300 m, the working face weighting step distance has the rule of "two small and one large." The two small weighting step distance is approximately $15 \mathrm{~m}$, and the next large weighting step distance is small, generally $8-11 \mathrm{~m}$, and the smallest one is $5 \mathrm{~m}$. The weighting strength also has the same rule. The two strong weighting steps and one general weighting step are associated with serious spalling, and the beam end distance is large. The average step distance is $16.4 \mathrm{~m}$.

When advancing to a distance of $300-634 \mathrm{~m}$, the working face also follows the rule of large and small step distance in terms of the weighting step distance. The large step distance is mostly in the range of $17-24 \mathrm{~m}$, and the small step distance is between 9 and $12 \mathrm{~m}$, which occurs alternately. The continuous long step period is mostly 2-4 (an individual is 1), and each small step period is 1 . There are also differences in compressive strength. The periodic weighting with a high strength generally lasts for a long time, and the weighting range is $30-110 \mathrm{bar}$. The weighting is concentrated, and the pressure in most areas ranges from 400 to 500 bar. When weighting, there is gangue leakage in the working face, and the roof is difficult to maintain. The pressure with a lower magnitude is generally divided into two sections: one section is $30-60$ bar at the head and the other section is 75-95 bar at the tail. The pressure magnitude is not high, mostly in the range of $300-350 \mathrm{bar}$, and the average pressure step is $16.4 \mathrm{~m}$. 


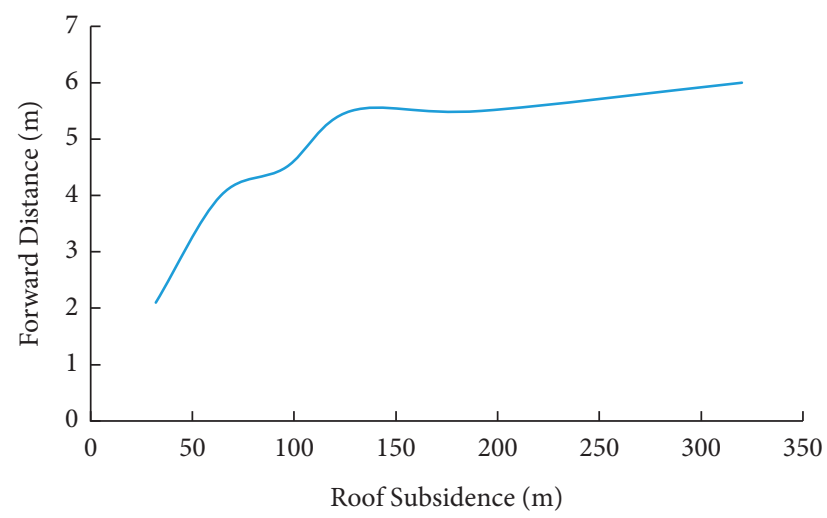

FIgURE 9: Relationship between advancing distance and roof settlement.

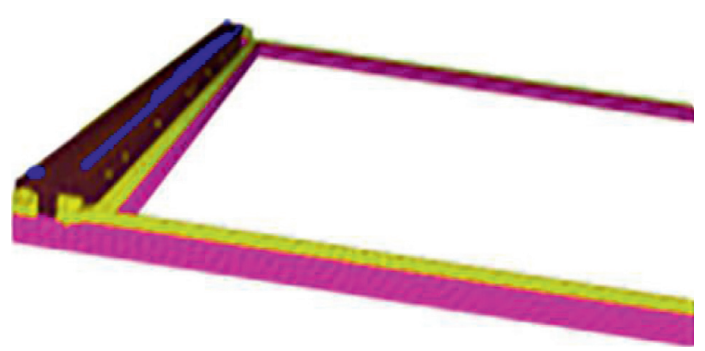

(a)

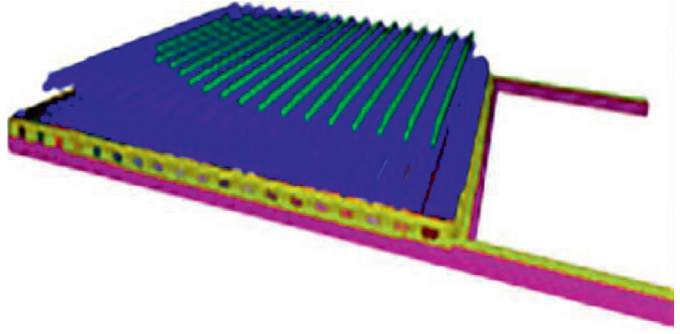

(b)

FIGURE 10: Characteristics of overburden collapse in different propulsion stages of the working face. (a) Advancing to $32 \mathrm{~m}$. (b) Advancing to $320 \mathrm{~m}$.

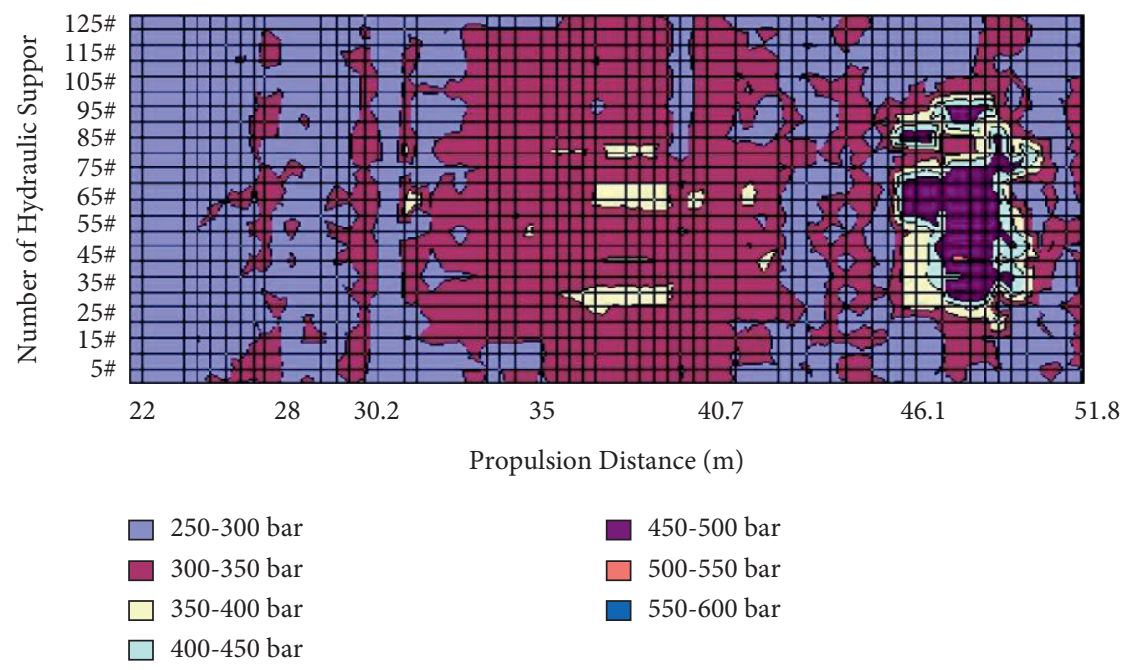

FIGURE 11: Resistance distribution of the primary pressure support.

The periodic weighting step distance of the 12511 working face with the $8 \mathrm{~m}$ mining height adjacent to the same coal seam is in the range of 7.2-16.8 $\mathrm{m}$, with an average of $10.7 \mathrm{~m}$ [29]. Compared with the 12401 working face, the average periodic weighting increase is approximately $1.4 \mathrm{~m}$.

4.2. Development Characteristics of Three Overburden Zones. To measure and analyze the development height of "three zones" in the 12401 working face and the characteristics of overburden caving, borehole sd1 was constructed at $1850 \mathrm{~m}$ in the advancing direction of the working face. The drilling depth was $187 \mathrm{~m}$, and the buried depth of the coal seam was $167 \mathrm{~m}$. Nine anchor displacement meters were installed to monitor the continuous settlement of the roof at different depths. The installation depths were $41,57,68$, $79,96,115,124,133$, and $141 \mathrm{~m}$. The corresponding heights from the coal seam were $126,110,99,88,71,52$, 43,34 , and $26 \mathrm{~m}$, respectively. Figure 12 shows the installation positions. 
Based on the measured results of the "three-zone" development characteristics of the overburden rock obtained by the borehole multipoint displacement meter, it can be concluded that the development height of the caving zone in the 12401 working face is $48 \mathrm{~m}$, which is 5.45 times the mining height, and the development height of the fracture zone is $108 \mathrm{~m}$, which is 12.27 times the mining height. During the advancing period of the working face, the overburden rock exists only in the caving and fracture zones where the bedrock is thin, and the bending subsidence zone changes with the change in the bedrock thickness. Figures 13 and 14 show the surface settlement curves.

\section{Determination of Working Resistance of Hydraulic Support}

5.1. Support Strength Calculation. Based on the above laws of overlying strata movement and evolution in the fully mechanized working face with a super-large mining height, when the working face with a shallow and thin bedrock advances rapidly, there are two instability forms of the broken rock blocks in the key strata based on the different roof control distances. When the top control distance is large, the key block loses its stability in the form of freefalling body and directly impacts the support of the working face. In the sliding process of the rock block, the front and rear-hinged surfaces can be considered to be under rolling friction. Therefore, the work done by friction can be ignored. Assuming that the direct roof is an elastic body and the loss of heat and sound energy is ignored in the impact process, the rock block " $\mathrm{A}$ " is completely pressed on the direct roof, and when the speed becomes zero again, its gravity increases. According to the principle of conservation of mechanical energy, we have

$$
Q_{1}(\Delta h+\Delta d)=\frac{1}{2} F_{d} \Delta d
$$

According to Hooke's law, the impact pressure $F_{\mathrm{d}}$ can be obtained using the following formula:

$$
F_{d}=\frac{E \Delta d}{\sum h} L_{s}
$$

When the gravity of the key block "a" acts on the direct roof in the form of static force, the deformation of the direct roof can be obtained using the following formula:

$$
\Delta_{s t}=\frac{Q_{1}}{E L_{s}} \sum h
$$

In the simultaneous (1)-(3), the maximum impact force on the immediate roof can be obtained as follows:

$$
F_{d}=\left(1+\sqrt{1+2 \frac{\Delta h}{\Delta_{s t}}}\right) Q_{1}=k_{d} Q_{1}
$$

The dynamic load coefficient increases with the increase in the amount of separation. Therefore, a sufficient initial support force should be maintained to prevent the separation between the direct roof and the basic roof. When the separation is 0 , the dynamic load coefficient is equal to 2 . Figure 15 shows the variation trend in the dynamic load coefficient with the amount of separation between the basic roof and the direct roof. In fact, the direct roof is not an ideal elastic body. When the key rock blocks act on it, the direct roof undergoes plastic deformation, and the dynamic load coefficient of the buffering rock blocks, that is, the impact pressure on the support, is between 1 and 2. A reasonable dynamic load coefficient can be selected on the basis of the thickness and mechanical properties of the working face.

If the roof control distance is small, the key block is prone to whirl instability. Based on the above analysis, when the rock block rotates forward to impact the gangue in the goaf, the influence of dynamic load on the support is not evident. Therefore, based on the instability when the rock block rotates backward, calculating the working resistance of the support is conducive to the safe production of the stope. Figure 16 shows the geometric relationship of the key block subjected to reverse rotation instability. The rock block "a" moves around the gangue contact point $\mathrm{O}$. When it rotates to the horizontal position, the displacement of the center of gravity of the rock block in the vertical direction can be obtained on the basis of the following geometric relationship:

$$
\Delta_{1}=\frac{\sin \left(\theta_{1}+\theta_{2}\right)-\sin \theta_{1}}{2 \cos \theta_{1}} L
$$

After turning to the horizontal position, the maximum settlement of the front hinge point of the key block can be expressed as

$$
\Delta_{2}=L \sin \theta_{2}
$$

Representing the above with $\Delta_{1}$ and $\Delta_{2}$, we have

$$
\begin{aligned}
\Delta_{1} & =\frac{\sin \left(\theta_{1}+\theta_{2}\right)-\sin \theta_{1}}{2 \cos \theta_{1} \sin \theta_{2}} \Delta_{2} \\
& =\frac{\sin \left(\theta_{1}+\theta_{2}\right)-\sin \theta_{1}}{2 \cos \theta_{1} \sin \theta_{2}}(\Delta d+\Delta h) .
\end{aligned}
$$

Substituting equations (6) into (7) yields

$$
n=\frac{\sin \left(\theta_{1}+\theta_{2}\right)-\sin \theta_{1}}{2 \cos \theta_{1} \sin \theta_{2}}
$$

The result is as follows:

$$
n Q_{1}(\Delta h+\Delta d)=\frac{1}{2} F_{d} \Delta d
$$

The simultaneous (2), (3), and (9) are as follows:

$$
F_{d}=n\left(1+\sqrt{1+2 \frac{\Delta h}{n \Delta_{s t}}}\right) Q_{1}=n k_{d} Q_{1} \text {. }
$$

From equation (10), we find that because the coefficient $n$ is $<1$, if there is a separation layer between the direct roof and the basic roof, the dynamic load coefficient increases rapidly. If $\Delta h=0$, the dynamic load coefficient is only related to $n$, 


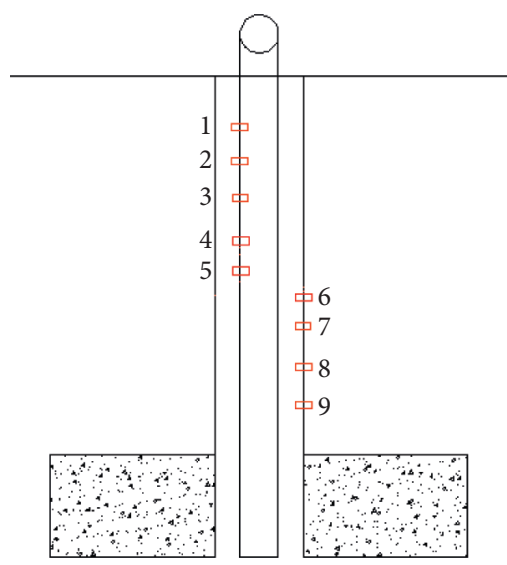

Figure 12: Installation diagram of multipoint displacement meters.

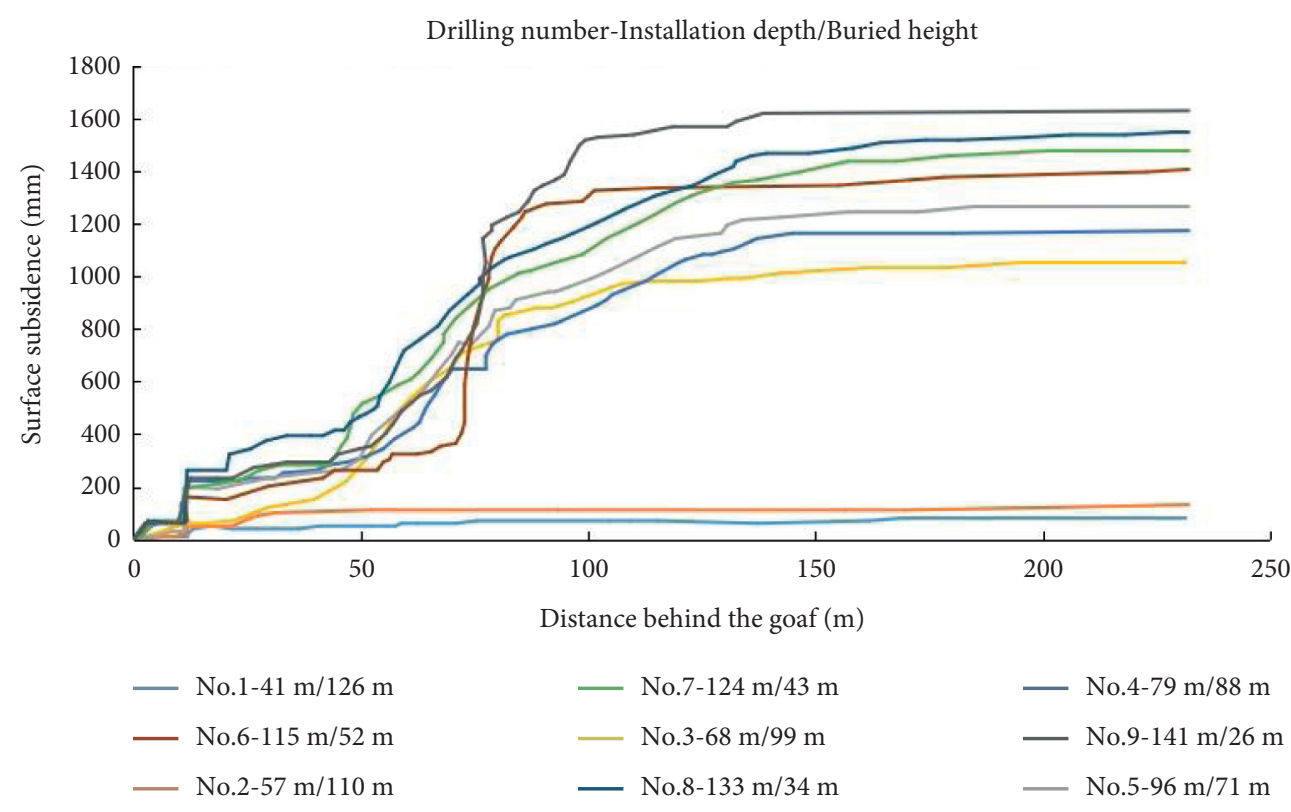

FIGURE 13: Displacement monitoring curves of displacement meters installed at different depths (relative surface displacement).

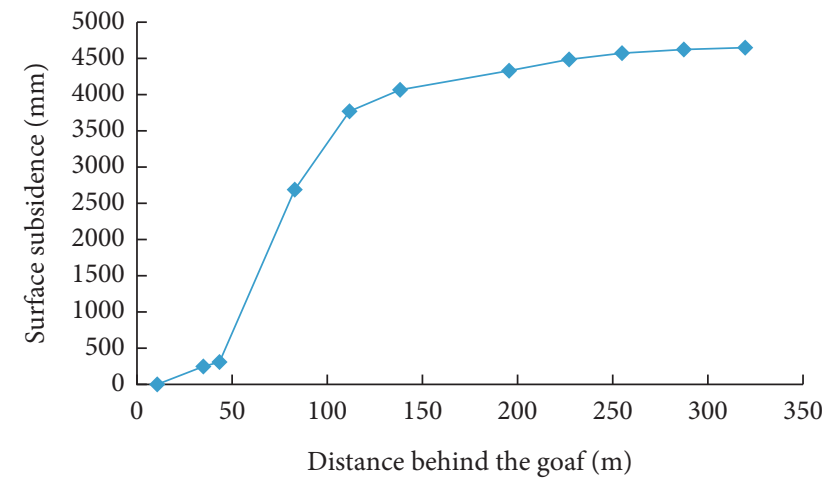

FIGURE 14: Surface subsidence curve.

and $n$ decreases with the increase in the turning angle $\theta_{2}$, as shown in the curve in Figure 17; however, the change range of the value of $n$ with the turning angle is narrow. To ensure

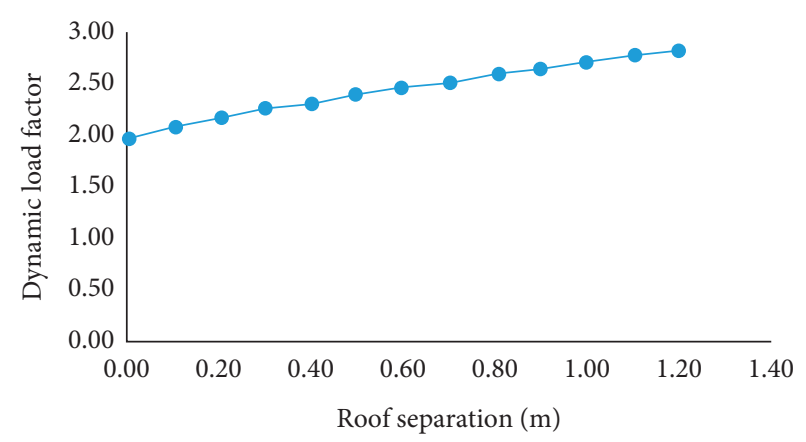

FIGURE 15: Variation trend in the dynamic load coefficient with bedding separation.

the safety of the working face, when the key block appears, there is a turning angle. When the formula is unstable, the value of $n$ can be uniformly selected as 0.6 . 


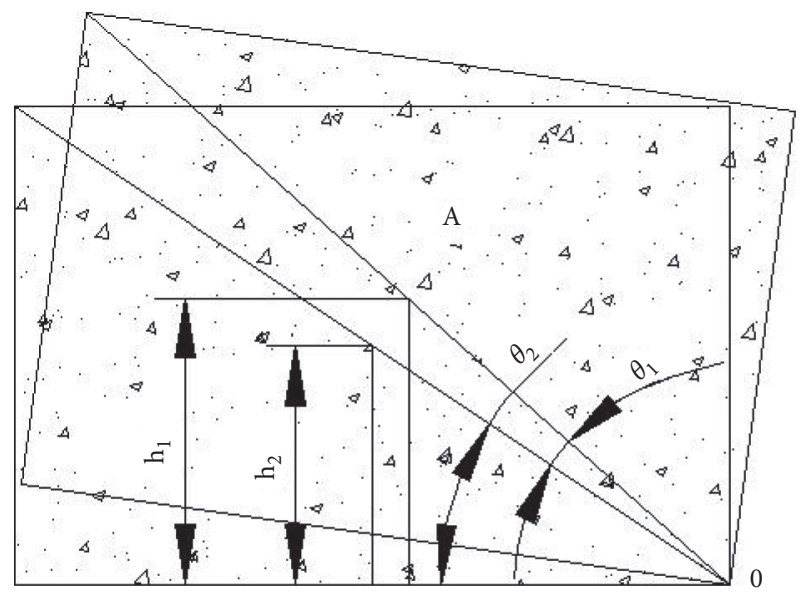

FIGURE 16: Geometric relationship between key block swing and instability.

5.1.1. Calculation of Support Height. The calculation of the maximum height of the support is shown in

$$
H Z_{\max } \geq M_{\max }+S_{1} .
$$

Therefore, $H Z_{\max } \geq 8600+200=8800 \mathrm{~mm}$.

The calculation of the minimum height of the support is

$$
H Z_{\text {min }} \leq M_{\min }-S_{1}-g-e .
$$

Therefore, $H Z_{\min }=6500-200-50-100=6150 \mathrm{~mm}$.

In conclusion, the selected support height is in the range of $4.0-8.8 \mathrm{~m}$, which meets the maximum and minimum support requirements.

5.1.2. Calculation of Support Height. The maximum height of the support can be calculated using

$$
H Z_{\max } \leq M_{\max }+S_{1} .
$$

Therefore, $H Z_{\max } \geq 8600+200=8800 \mathrm{~mm}$.

The minimum height of the support can be calculated using

$$
H Z_{\min } \leq M_{\min }-S_{2}-g-e .
$$

Therefore, $H Z_{\min }=6500-200-50-100=6150 \mathrm{~mm}$.

In conclusion, the selected support height is in the range of $4.0-8.8 \mathrm{~m}$, which meets the maximum and minimum support requirements.

5.1.3. Calculation of Support Strength. Two empirical formulae are used to calculate the maximum value.

Formula 1:

$$
P=9.81 h r k \text {. }
$$

Therefore, $\quad P=9.81 \mathrm{hrk}=9.81 \times 8.6 \times 2.5 \times 7=1476.40$ $\left(\mathrm{kN} / \mathrm{m}^{2}\right)=1.47 \mathrm{MPa}$.

Formula 2:

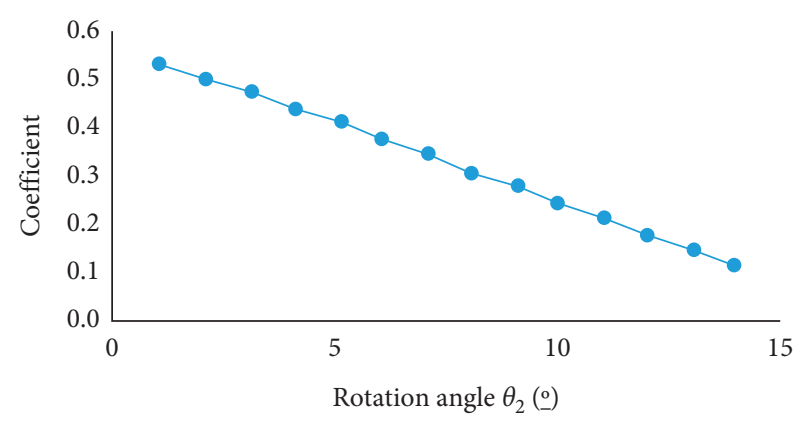

FIGURE 17: Relationship between coefficient $n$ and the reverse angle.

$$
\begin{aligned}
& \frac{9.8 h \cdot r \cdot K d \cdot B}{1000(K-1) \cos a} \\
& \frac{9.8 h \cdot r \cdot n \cdot \cos a}{1000(K-1)} .
\end{aligned}
$$
1.3 .

The dynamic load coefficient of the roof $K_{d}$ is taken as

Therefore, $a, \quad P \geq 9.8 \times 8.6 \times 2.5 \times 1.3 \times 1.2 \times \cos 3^{\circ} / 1000$ $(1.25-1)=1.31 \mathrm{MPa}, b, P \geq 9.8 \times 8.6 \times 2.5 \times 1.75 \times \cos 3^{\circ} / 1000$ $(1.25-1)=1.47 \mathrm{MPa}$.

Based on the empirical formula, the maximum support strength obtained using the two calculation methods is 1.47 MPa; hence, the support strength of the hydraulic support in the working face should not be less than $1.47 \mathrm{MPa}$.

5.2. Length Effect of Working Face on Hydraulic Support Resistance. The adaptability of the working face support and stope safety are important factors in the selection of the inclined length of the working face. A reasonable inclined length should minimize the grade of the strata behavior strength of the stope under certain mining technical conditions, i.e., to achieve low resistance and short time weighting. After the fracture around the basic roof, because of the change in the support conditions, its rotation angle increases rapidly. If the working face length is small and the bearing capacity of the surrounding simply supported basic roof strata is greater than that of the fractured strata, the middle fracture line of the basic roof will lag behind the surrounding fracture line for a certain duration, as shown in Figure 18(a). At this time, due to the support of the surrounding coal pillars and coal bodies, the support only bears deformation. The results show that the load, the working resistance, and the shrinkage of the movable column are low, and there is no phenomenon of pressing the frame due to the small free stroke. The thickness of the follow-up load layer on the roof increases with the increase in the working face length. If the inclined length of the working face is increased, the bearing capacity of the basic roof will be lower than the load of the follow-up strata after the fracture around the basic roof. In this case, the second fracture occurs quickly, there will be a middle fracture line, and the working face starts to press, as shown in Figure 18(b). In the early stage of 


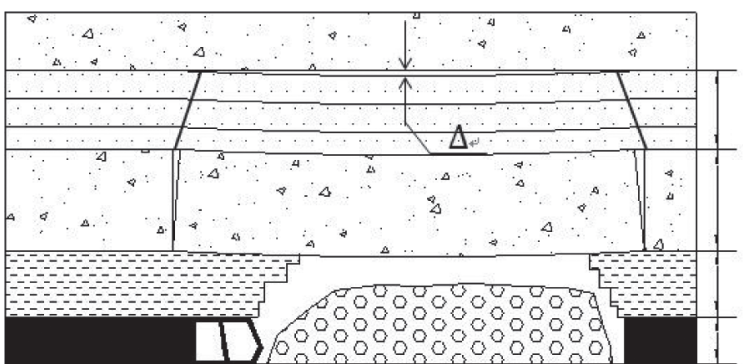

(a)

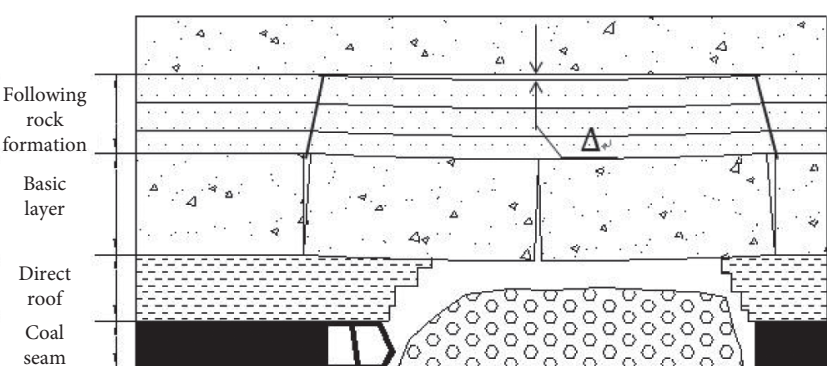

(b)

FIGURE 18: Fracture morphology of the overburden rock in a shallow-buried stope.

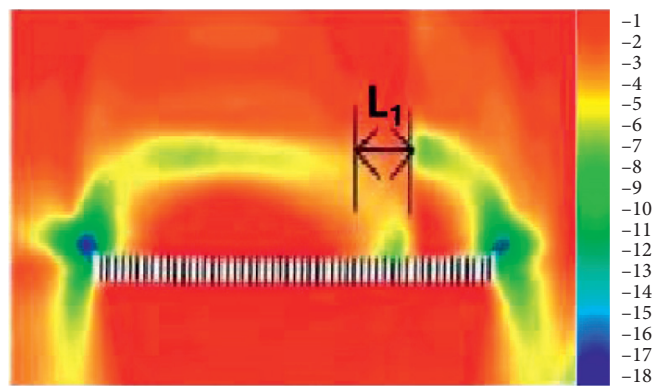

(a)

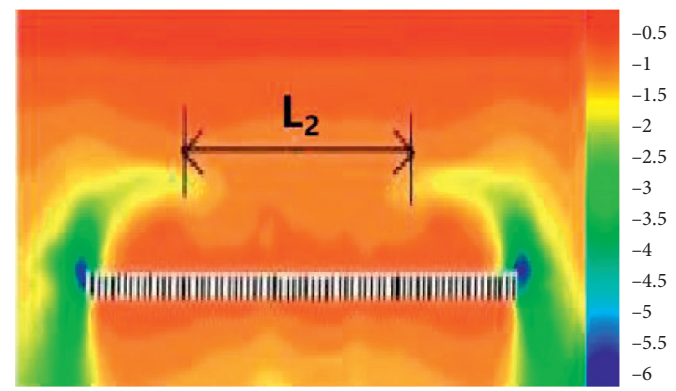

(b)

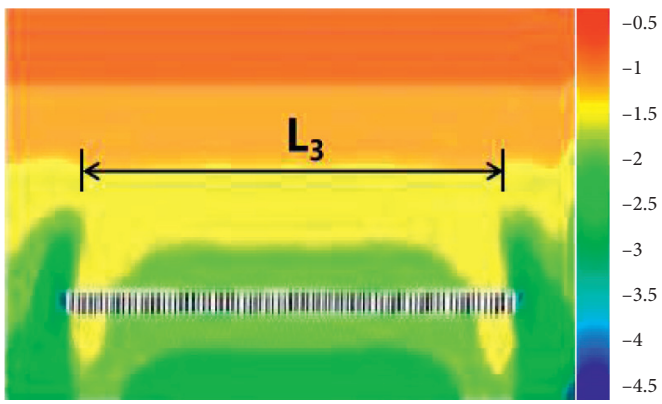

(c)

Figure 19: Maximum principal stress distribution of overburden at different lengths (unit: MPa). (a) $240 \mathrm{~m}$. (b) $300 \mathrm{~m}$. (c) $360 \mathrm{~m}$.

the middle fault line, the rotation angle of the fractured rock block is small and can keep the balance under the support. The support bears the gravity of the direct roof, a part of the basic roof, and the follow-up strata. With the advancement of the working face, the balance structure loses its stability. The gravity forces of the basic roof fractured rock block and the follow-up strata act on the support, and the support changes from the "given deformation" working state to the working state "under the working condition of a given load," and its resistance increases rapidly. If the working face is too long and if the middle fracture line of the basic roof and the surrounding fracture line appear simultaneously, the rotation time of the fractured rock block of the basic roof will be sufficient, the subsidence will be large, the support of the working face will always be in the state of high working resistance, and the continuous pressure distance of the working face will be large. In a typical thin bedrock stope, when the basic roof is under pressure, the bedrock exhibits full-thickness fractures, and there is no pressure relief phenomenon after the first fracture around the basic roof. Therefore, the fracture line around the stope and the middle fracture line occur simultaneously, and the basic roof movement is violent, which is also the reason for the high magnitude of the ground pressure and the evident impact of the dynamic load on the support in typical shallow stopes. In conclusion, in the mining of shallow coal seams, the length of the working face with the dynamic load being equal to the ultimate bearing capacity of the simply supported roof is most reasonable.

In the advancing process of the working face, there is an arched bearing area with a high stress level in the overburden, namely, the stress shell. The working face is under the cover of this structure, and the support only bears a part of the weight of the broken rock in the shell; therefore, the working resistance is high, and the control effect of the surrounding rock is good. The rated working resistance of the 12401 working face support is $26000 \mathrm{kN}$ (1.71-1.83 MPa), and the maximum support strength is 
$2 \mathrm{MPa}$. Three numerical models are established on the basis of the characteristics of the roof and floor strata of the 12401 working face. The working face lengths are 240, 300, and $360 \mathrm{~m}$. Figure 19 shows the numerical calculation results.

When the working face is $240 \mathrm{~m}$, there is a relatively complete stress shell in the overburden. Because the support sliding and roof falling are within the $L_{1}$ range, the surrounding rock control effect is poor, resulting in the disappearance of the narrow range of the stress shell. However, the support on the working face as a whole bears a uniform stress, and the load is in the range of $0-1 \mathrm{MPa}$. When the working face is $300 \mathrm{~m}$ long, the roof bedrock fracture occurs within $L_{2}$ above the middle part, and the stress is high. The load at both ends is low, and the load in the middle is high; however, the load value remains in the range of $0.8-1.6 \mathrm{MPa}$. Therefore, the $300 \mathrm{~m}$ long working face with a rated working resistance of $26000 \mathrm{kN}$ support can achieve safe mining. When the working face is $360 \mathrm{~m}$ long, there is no longer an arch stress bearing area in the overburden rock, the bedrock is broken as a whole, and the protection of the stress shell is lost. The load of the working face support is increased, up to $2.5-3 \mathrm{MPa}$, which is greater than the rated support strength of the selected support, and the safety of the working face cannot be ensured. In conclusion, it is reasonable to select an inclined length of $300 \mathrm{~m}$ for the 12401 working face.

\section{Conclusion}

By comparing and analyzing the results of similarity simulation experiment, numerical simulation, and field measurement, we can conclude that the results of the simulation experiment and numerical simulation calculation are reliable. We obtained the heights of the overburden caving zone, fracture zone, and bending subsidence zone and determined the distribution characteristics of the overburden displacement field in the advancing process of the 12401 working face. Our results can provide a reference for the support selection of super-large-mining-height fully mechanized mining faces. The conclusions drawn from the results are as follows:

(1) The characteristics of the working face pressure behavior in the $8.8 \mathrm{~m}$ super-high mining face are as follows. (1) Compared with the $8 \mathrm{~m}$ working face in the same coal seam of adjacent mines, the initial weighting step is increased by $7 \mathrm{~m}$, the average periodic weighting step is shortened by $1.4 \mathrm{~m}$, and the weighting behavior is more intense. (2) The lower the advancing speed of the working face, the shorter the weighting step. As the advancing process accelerates, the weighting step increases. Each weighting is associated with evident weighting and nonweighting limits. However, because of the larger stope space, the higher the advancing speed, the higher the risk of roof disaster. (3) In the initial advancing process of the working face, the main characteristic of the mine pressure behavior is the frequent destruction of the coal wall.
(2) From the evolutionary characteristics of overburden movement and surface subsidence with the advancement of an $8.8 \mathrm{~m}$ super-high working face, the following conclusions can be drawn. (1) Large fractures near the working face are closely related to the downhole pressure. When periodic pressure occurs at the working face, there will be small fractures on the surface. (2) The development of the "three zones" is that the height of the caving zone is $48 \mathrm{~m}$, which is 5.45 times the mining height, and the height of the fissure zone is $108 \mathrm{~m}$, which is 12.27 times the mining height. During the advance of the working face, there are only caving and fissure zones in the overburden of the thin bedrock, and the bending subsidence zone changes with the change in the bedrock thickness.

(3) Through the theoretical calculation and numerical simulation, it is concluded that the support strength of the hydraulic support in the $8.8 \mathrm{~m}$ super-high working face should not be less than $1.47 \mathrm{MPa}$.

\section{Nomenclature}

$Q_{1}$ : $\quad$ Gravity of the direct top and load layer $(\mathrm{kN})$

$\triangle h$ : Amount of separation between the direct top and the basic roof block $(\mathrm{m})$

$\triangle d: \quad$ Deformation of the direct top $(\mathrm{m})$

$F_{d}: \quad$ Impact force on the direct top $(\mathrm{kN})$

E: $\quad$ Modulus of elasticity of direct jacking (GPa)

$L_{s}: \quad$ Top control distance $(\mathrm{m})$

$\triangle_{\mathrm{st}}$ : Deformation of the direct roof under static force (m)

$K_{d}: \quad$ Dynamic load coefficient of key block "a" in freefalling instability

$H Z_{\text {max }}$ : Maximum support height of coal seam (mm)

$M_{\text {max }}$ : Maximum mining height of fully mechanized face (mm), $8600 \mathrm{~mm}$

$S_{1}$ : $\quad$ Maximum thickness of the first collapse of the false roof $(\mathrm{mm}), 200 \mathrm{~mm}$

$H Z_{\text {min }}$ : Minimum support height of coal seam (mm)

$M_{\text {min }}$ : Minimum mining height of the fully mechanized face $(\mathrm{mm}), 6500 \mathrm{~mm}$

$\mathrm{S}_{2}$ : $\quad$ Roof subsidence $(\mathrm{mm}), 200 \mathrm{~mm}$

$g$ : Thickness of the floating gangue on the top beam and under the base $(\mathrm{mm}), 50 \mathrm{~mm}$

$e$ : $\quad$ Retraction amount of the support when moving (mm), $100 \mathrm{~mm}$

$P$ : $\quad$ Reasonable support strength of the fully mechanized face $\left(\mathrm{kN} / \mathrm{m}^{2}\right)$

$h$ : $\quad$ Mining height $(\mathrm{m}), 8.6 \mathrm{~m}$

$r$ : $\quad$ Gravity density of roof rock $\left(\mathrm{t} / \mathrm{m}^{3}\right), 2.5 \mathrm{t} / \mathrm{m}^{3}$

$k$ : $\quad$ The ratio of the thickness of the overlying strata to the mining height that the support should support in the fully mechanized face is generally in the range of $4-8$. When the mining seam is thick, the roof condition is poor and the periodic weighting is evident, a high multiple should be selected. Based on the mining situation of the adjacent fully mechanized face, 7 is selected herein 
a: $\quad$ Coal seam inclination $\left({ }^{\circ}\right), 3^{\circ}$

$B$ : $\quad$ Additional resistance coefficient, 1.2

n: $\quad$ Unbalanced safety factor, 1.75

$K$ : $\quad$ Coefficient of slate crushing and swelling, 1.25.

\section{Data Availability}

The data used to support the findings of this study are included within the article.

\section{Conflicts of Interest}

There are no conflicts of interest regarding the publication of this paper.

\section{Acknowledgments}

This study was supported by the State Key Research Development Program of China (Grant no. 2017YFC0804310) and China Postdoctoral Science Foundation (2020M680490).

\section{References}

[1] J. L. Xu and J. F. Ju, "Structural morphology of key strata and its influence on the development of ore pressure in fullmechanized face of extra-large mining," Journal of Rock Mechanics and Engineering, vol. 30, no. 3, pp. 342-348, 2013.

[2] J. Ju and J. Xu, "Structural characteristics of key strata and strata behaviour of a fully mechanized longwall face with $7.0 \mathrm{~m}$ height chocks," International Journal of Rock Mechanics and Mining Sciences, vol. 58, no. 3, pp. 46-54, 2013.

[3] L. H. Sun, "Study on overburden structure evolution and orepressure activity law of weakly consolidated Large mining face in western China," Journal of Rock Mechanics and Engineering, vol. 36, no. 7, p. 1820, 2017.

[4] P. Xiang, L. H. Sun, H. G. Ji, Y. Gao, Y. J. Liu, and Y. F. Li, "Dynamic distribution characteristics and Determination method of caving zone on large mining height working face," Journal of Mining and Safety Engineering, vol. 34, no. 5, pp. 861-867, 2017.

[5] Q. X. Huang and J. L. Zhou, "Study on coal pressure law and roof structure of large mining face in shallow coal seam," Acta Coal Sinica, vol. 41, no. S2, pp. 279-286, 2016.

[6] S. Mahdi and C. Li. Charlie, "Analytical approaches for studying the stability of laminated roof strata," International Journal of Rock Mechanics and Mining Sciences, vol. 79, no. 10, pp. 99-108, 2015.

[7] W. Zhu, J. Xu, J. Xu, D. Chen, and J. Shi, "Pier-column backfill mining technology for controlling surface subsidence," International Journal of Rock Mechanics and Mining Sciences, vol. 96, pp. 58-65, 2017.

[8] Y. H. Pang, G. F. Wang, J. H. Zhang et al., "Overburden fracture structure and stability Control Technology of superlarge Mining face," Coal Science and Technology, vol. 45, no. 11, pp. 45-50, 2017.

[9] M. Shabanimashcool and C. C. Li, "Analytical approaches for studying the stability of laminated roof strata," International Journal of Rock Mechanics and Mining Sciences, vol. 79, no. 10, pp. 99-108, 2015

[10] A. J. Das, P. K. Mandal, R. Bhattacharjee, S. Tiwari, A. Kushwaha, and L. B. Roy, "Evaluation of stability of underground workings for exploitation of an inclined coal seam by the ubiquitous joint model," International Journal of Rock Mechanics and Mining Sciences, vol. 93, no. 3, pp. 101-114, 2017.

[11] H. J. Hao, J. Wu, Y. Zhang, and Z. B. Yuan, "Balance structure of upper strata in large mining height and its influence on the appearance of stope ore pressure," Acta Coal Sinica, vol. 29, no. 2, pp. 137-141, 2004.

[12] H. J. Hao, Y. Zhang, and Z. B. Yuan, "Overall mechanical model of large stope and influence of mine pressure development," Mine Pressure and Roof Management, vol. 1, pp. 21-24, 2003.

[13] Y. P. Fu, D. F. Song, and P. W. Xing, "Research on caving zone Height of shallow coal Seam overlong working face with Large Mining Height," Journal of Mining and Safety Engineering, vol. 27, no. 2, pp. 190-194, 2010.

[14] S. L. Yang, Z. H. Wang, and D. Z. Kong, "Evolution process of overburden fracture and determination of support resistance in high stope," Journal of Mining and Safety Engineering, vol. 33, no. 2, pp. 199-207, 2016.

[15] G. Cheng, T. Ma, C. Tang, H. Liu, and S. Wang, "A zoning model for coal mining - induced strata movement based on microseismic monitoring," International Journal of Rock Mechanics and Mining Sciences, vol. 94, no. 3, pp. 123-138, 2017.

[16] S. Huang, Y. Lyu, Y. Peng, and M. Huang, "Analysis of factors influencing rockfall runout distance and prediction model based on an improved KNN algorithm," IEEE ACCESS, vol. 7, pp. 66739-66752, 2019.

[17] G. F. Wang and Y. H. Pang, "Coupling relationship between hydraulic support and surrounding rock and its application," Acta Coal Sinica, vol. 40, no. 1, pp. 30-34, 2015.

[18] G. F. Wang, Y. H. Pang, and H. W. Ren, "Coal safe and efficient mining theory, technology and equipment innovation prac-lice," Journal of China Coal Society, vol. 43, no. 4, pp. 903-913, 2018.

[19] A. J. Das, P. K. Mandal, R. Bhattacharjee, S. Tiwari, A. Kushwaha, and L. B. Roy, "Evaluation of stability of underground workings for exploitation of an inclined coal seam by the ubiquitous joint model," International Journal of Rock Mechanics and Mining Sciences, vol. 93, no. 3, pp. 101-114, 2017.

[20] S. Di, J. R. Wang, and G. J. Song, "Study on rib spalling characteristics of $8.5 \mathrm{~m}$ height fully-mechanized mining face," Coal Science and Technology, vol. 45, no. 9, pp. 97-102+115, 2017.

[21] X. Ding, X.-c. Xiao, D. Wu, and X.-f. Lv, "Mechanical properties and charge signal characteristics in coal material failure under different loading paths," International Journal of Coal Science \& Technology, vol. 6, no. 1, pp. 138-149, 2019.

[22] H. Wang, X. Fang, Y. Li, Z. Zheng, and J. Shen, "Research and application of the underground fire detection technology based on multi-dimensional data fusion," Tunnelling and Underground Space Technology, vol. 109, no. 109, p. 103753, 2021.

[23] D. Xue, J. Zhou, Y. Liu, and L. Gao, "On the excavationinduced stress drop in damaged coal considering a coupled yield and failure criterion," International Journal of Coal Science \& Technology, vol. 7, no. 1, pp. 58-67, 2020.

[24] F. Du, K. Wang, and X. Zhang, "Experimental study of coalgas outburst: insights from coal-rock structure, gas pressure and adsorptivity," Natural Resources Research, vol. 29, no. 6, pp. 2481-2493, 2020.

[25] L. Dou, K. Yang, and X. Chi, "Fracture behavior and acoustic emission characteristics of sandstone samples with inclined 
precracks," International Journal of Coal Science \& Technology, vol. 8, no. 1, pp. 77-87, 2021.

[26] J. Wang, S. Yang, and D. Kong, "Failure mechanism and control technology of longwall coalface in large-cuttingheight mining method," International Journal of Mining Science and Technology, vol. 26, no. 1, pp. 111-118, 2016.

[27] L. Qiu, Z. Liu, E. Wang, X. He, J. Feng, and B. Li, "Earlywarning of rock burst in coal mine by low-frequency electromagnetic radiation," Engineering Geology, vol. 279, no. 279, p. 105755, 2020.

[28] H. Wang, X. Fang, F. Du et al., "Three-dimensional distribution and oxidation degree analysis of coal gangue dump fire area: a case study," The Science of the Total Environment, vol. 772, no. 772, p. 145606, 2021.

[29] G. F. Wang, Y. H. Peng, M. Z. Li, and Y. Ma, "Coupling effect between Hydraulic support and surrounding rock on super High Mining Face," Acta Coal Sinica, vol. 42, no. 2, pp. 518-526, 2017.

[30] J. C. Wang, F. Liu, and L. Wang, "Coal scientific mining and mining science," Acta Coal Sinica, vol. 41, no. 11, pp. 26512660, 2016.

[31] A. Zhang, "Analysis on the breaking structure and movement law of overlying strata in extra-thick coal seam," Energy Technology and Management, vol. 44, no. 6, pp. 83-84, 2019.

[32] L. H. Zhang and N. N. Li, "CStudy on strata behavior law offully-mechanized mining face with $8 \mathrm{~m}$ large mining height," Coal Science and Technology, vol. 45, no. 11, pp. 21-26, 2017. 